\title{
Band structure engineered tunneling heterostructures for high-performance visible and near-infrared photodetection
}

\author{
Fakun Wang, Peng Luo, Yue Zhang, Yu Huang, Qingfu Zhang, Yuan Li and Tianyou Zhai*
}

\begin{abstract}
Tunneling heterostructures are emerging as a versatile architecture for photodetection due to their advanced optical sensitivity, tailorable detection band, and wellbalanced photoelectric performances. However, the existing tunneling heterostructures are mainly operated in the visible wavelengths and have been rarely investigated for the nearinfrared detection. Herein, we report the design and realization of a novel broken-gap tunneling heterostructure by combining $\mathrm{WSe}_{2}$ and $\mathrm{Bi}_{2} \mathrm{Se}_{3}$, which is able to realize the simultaneous visible and near-infrared detection because of the complementary bandgaps of $\mathrm{WSe}_{2}$ and $\mathrm{Bi}_{2} \mathrm{Se}_{3}(1.46$ and $0.3 \mathrm{eV}$, respectively). Thanks to the realigned band structure, the heterostructure shows an ultralow dark current below picoampere and a high tunneling-dominated photocurrent. The photodetector based on our tunneling heterostructure exhibits a superior specific detectivity of $7.9 \times 10^{12}$ Jones for a visible incident of $532 \mathrm{~nm}$ and $2.2 \times 10^{10}$ Jones for a $1456 \mathrm{~nm}$ nearinfrared illumination. Our study demonstrates a new band structure engineering avenue for the construction of van der Waals tunneling heterostructures for high-performance wide band photodetection.
\end{abstract}

Keywords: band structure engineering, van der Waals tunneling heterostructures, $\mathrm{Bi}_{2} \mathrm{Se}_{3} / \mathrm{WSe}_{2}$, photodetector, visible and nearinfrared detection

\section{INTRODUCTION}

Van der Waals heterostructures (vdWHs) based on vertically stacked two-dimensional (2D) layered semiconductors have been extensively investigated due to their peculiar physical characteristics and potential applications in electronics and optoelectronics [1-4]. Benefiting from the strong light-matter interaction of the atomicallythin 2D layered semiconductors [5], plenty of $\mathrm{vdWH}$ devices have demonstrated promising performances for photodiodes [6,7], phototransistor [8] and other photodetectors [9-13]. However, the unsatisfactory balance in the performances such as detectivity (light on/off ratio), responsivity and response rate (rise/decay time) has usually been observed in the existing photodetectors [1417].

With this regard, the tunneling heterostructures are widely studied as promising alternative candidates due to their tunable carrier tunneling mechanisms. With proper band structure alignment, such tunneling heterostructures can likely reach outstanding photodetection performances of the device while keeping a good balance in various photoelectric parameters [18-21]. For instance, $\mathrm{Vu}$ et al. [19] found that the multilayered $\mathrm{MoS}_{2} / \mathrm{h}-\mathrm{BN} /$ graphene tunneling heterostructure can exhibit simultaneously improved detectivity $\left(2.6 \times 10^{13}\right.$ Jones $)$ and responsivity $\left(180 \mathrm{~A} \mathrm{~W}^{-1}\right)$ by adjusting the asymmetric tunneling effect of dark-carriers and photocarriers in the heterostructure. Recently, our group [20] reported a type of broken-gap tunneling diode consisting of few-layer $\mathrm{WSe}_{2}$ and $\mathrm{SnS}_{2}$. The device demonstrated excellent and well-balanced performances in responsivity $\left(244 \mathrm{~A} \mathrm{~W}^{-1}\right)$, detectivity $\left(1.29 \times 10^{13}\right.$ Jones $)$, and response rate $(13 / 24 \mathrm{~ms})$ under a $550-\mathrm{nm}$ illumination, attributed to the large mismatch of the band structure [20]. While the optoelectronic performances of these tunneling heterostructure devices are promising, their detection band is mainly limited in the visible region $[19,20]$. Recently, a type of reverse rectifying AsP/InSe tunneling hetero-

State Key Laboratory of Material Processing and Die \& Mould Technology, School of Material Sciences and Engineering, Huazhong University of Science and Technology, Wuhan 430074, China

${ }^{*}$ Corresponding author (email: zhaity@hust.edu.cn) 
junction was reported for a spectral detection capability up to $1550 \mathrm{~nm}$, but the responsivity are fairly low $(\sim 1 \times$ $10^{-3} \mathrm{~A} \mathrm{~W}^{-1}$ ) and far from practical application [22]. To date, the realization of high-performance near-infrared detection or wide band detection with well-balanced detectivity, responsivity and response/recovery time on these tunneling heterostructures is still a big challenge.

Toward this end, herein we present a band structure engineering strategy to construct the van der Waals tunneling heterostructures with wide-gap ( $\mathrm{WSe}_{2}, 1.46 \mathrm{eV}$ ) and narrow-gap $\left(\mathrm{Bi}_{2} \mathrm{Se}_{3}, 0.3 \mathrm{eV}\right)$ semiconductors. The presence of both wide and narrow bandgaps in the heterostructure allows for its wide band light absorption from the visible to near-infrared region. Meanwhile, the non-overlapping band alignments of the two stacked materials prompt the photo-generated carriers to transport in the channel by the tunneling mechanism, resulting in the generation of significant photocurrents. As a result, our $\mathrm{Bi}_{2} \mathrm{Se}_{3} / \mathrm{WSe}_{2}$ tunneling heterostructure can not only maintain excellent and well-balanced optoelectronic performances, but also realize a wide band photodetection. The resultant photodetector exhibits specific detectivity of $7.9 \times 10^{12}$ Jones and responsivity of $94.26 \mathrm{~A} \mathrm{~W}^{-1}$ for the $532 \mathrm{~nm}$ visible source, and specific detectivity of $2.2 \times 10^{10}$ Jones and responsivity of $3 \mathrm{~A} \mathrm{~W}^{-1}$ for the $1456 \mathrm{~nm}$ near-infrared source. Its near-infrared responsivity is $\sim 3 \times 10^{3}$ times higher than that of the previously reported InSe/AsP photodetector [22]. This manifests that the tunneling heterostructure with complementary bandgaps can provide an available platform for high-performance wide band photodetection.

\section{EXPERIMENTAL SECTION}

\section{Fabrication of the $\mathrm{Bi}_{2} \mathrm{Se}_{3} / \mathrm{WSe}_{2}$ heterostructure}

First, $2 \mathrm{D} \mathrm{Bi}_{2} \mathrm{Se}_{3}$ flakes were grown on mica substrates by using physical vapor deposition. The $\mathrm{Bi}_{2} \mathrm{Se}_{3}$ powder was placed in the center of a horizontal tube furnace equipped with a quartz tube and the flurophlogopite mica substrates were placed in the downstream $8-12 \mathrm{~cm}$ away from center. High purity Ar gas was used to carry $\mathrm{Bi}_{2} \mathrm{Se}_{3}$ vapor from the furnace center for the synthesis of $2 \mathrm{D}$ $\mathrm{Bi}_{2} \mathrm{Se}_{3}$ flakes. For optimized synthesis, the furnace was heated to $600^{\circ} \mathrm{C}$ and kept at this temperature for $30 \mathrm{~min}$ with Ar carrier gas flow of $100 \mathrm{sccm}$. The furnace cooled naturally to room temperature with a flowing Ar gas. 2D $\mathrm{Bi}_{2} \mathrm{Se}_{3}$ flakes were grown on the mica substrates. Then, the $\mathrm{Bi}_{2} \mathrm{Se}_{3}$ flakes were then transferred to a $\mathrm{Si} / \mathrm{SiO}_{2}$ $(300 \mathrm{~nm})$ substrate via spinning poly(methyl methacrylate) (PMMA) and poly(propylene carbonate) (PPC) as the supporting membrane. Next, the exfoliated $\mathrm{WSe}_{2}$ flake on a polydimethylsiloxane (PDMS) stamp was transferred onto the $\mathrm{Bi}_{2} \mathrm{Se}_{3}$ flake using a precision transfer system. Finally, the electrode patterns were defined by typical electron beam lithography (FEI Quanta 650 scanning electron microscope and Raith Elphy Plus, USA) and deposited by thermally evaporating 10/50 nm $\mathrm{Cr} / \mathrm{Au}$ (Nexdep, Angstrom Engineering).

\section{Characterizations}

Optical microscope (BX51, OLMPUS, Japan) and atomic force microscope (AFM; Dimension Icon, Bruker, Germany) were utilized to characterize the morphology and thickness of the heterostructure. Raman and photoluminescence (PL) spectra were investigated by a confocal microscope spectrometer (Alpha 300R, WITec) together with 532 laser source. The electronic and photoelectronic measurements of the $\mathrm{Bi}_{2} \mathrm{Se}_{3} / \mathrm{WSe}_{2}$ heterostructure were performed by using an Agilent B1500A semiconductor analyzer (USA) in a Lakeshore probe station. Power adjustable 532- and 1456-nm lasers were used to record the photoelectric response of the heterostructure.

\section{RESULTS AND DISCUSSION}

The heterostructure was assembled by a dry transfer process. The $\mathrm{Bi}_{2} \mathrm{Se}_{3}$ flakes were initially grown on a mica substrate via physical vapor deposition [23-25] and then transferred onto a surface-oxidized $\mathrm{Si}\left(\mathrm{Si} / \mathrm{SiO}_{2}\right)$ substrate by the PMMA and PPC-assisted transfer method. In the following, the $\mathrm{WSe}_{2}$ flakes were mechanically exfoliated and further transferred onto the top of $\mathrm{Bi}_{2} \mathrm{Se}_{3}$. The final fabrication of $\mathrm{Bi}_{2} \mathrm{Se}_{3} / \mathrm{WSe}_{2}$ heterostructure device was completed via standard electron-beam lithography, where the $10 / 50 \mathrm{~nm} \mathrm{Cr} / \mathrm{Au}$ electrodes were deposited by thermal evaporation. Details about the experimental process are provided in the Experimental Section and Fig. S1. Fig. 1a demonstrates the 3D schematic structure of our van de Waals tunneling photodetector, and an optical microscopic image of the $\mathrm{Bi}_{2} \mathrm{Se}_{3} / \mathrm{WSe}_{2}$ heterostructure is provided in Fig. 1b. The thicknesses of $\mathrm{Bi}_{2} \mathrm{Se}_{3}$ and $\mathrm{WSe}_{2}$ were determined to be $10.5 \mathrm{~nm}(10 \mathrm{~L})$ and $5.6 \mathrm{~nm}(8 \mathrm{~L})$, respectively (Fig. 1c).

The electronic band alignment of the $\mathrm{Bi}_{2} \mathrm{Se}_{3} / \mathrm{WSe}_{2}$ heterostructure was further clarified by ultraviolet photoemission spectroscopy, as shown in Fig. S2. The work function (WF) of $\mathrm{Bi}_{2} \mathrm{Se}_{3}$ and $\mathrm{WSe}_{2}$ is determined by the equation of $\mathrm{WF}=h v-E_{\mathrm{S}}[26,27]$, where $h v$ is the incident photon energy $(21.2 \mathrm{eV})$, and $E_{\mathrm{S}}$ is the binding energy of the secondary electron cut-off (Fig. S2b, d). We obtained the WF values of 3.86 and 4.61 for $\mathrm{WSe}_{2}$ and $\mathrm{Bi}_{2} \mathrm{Se}_{3}$, 

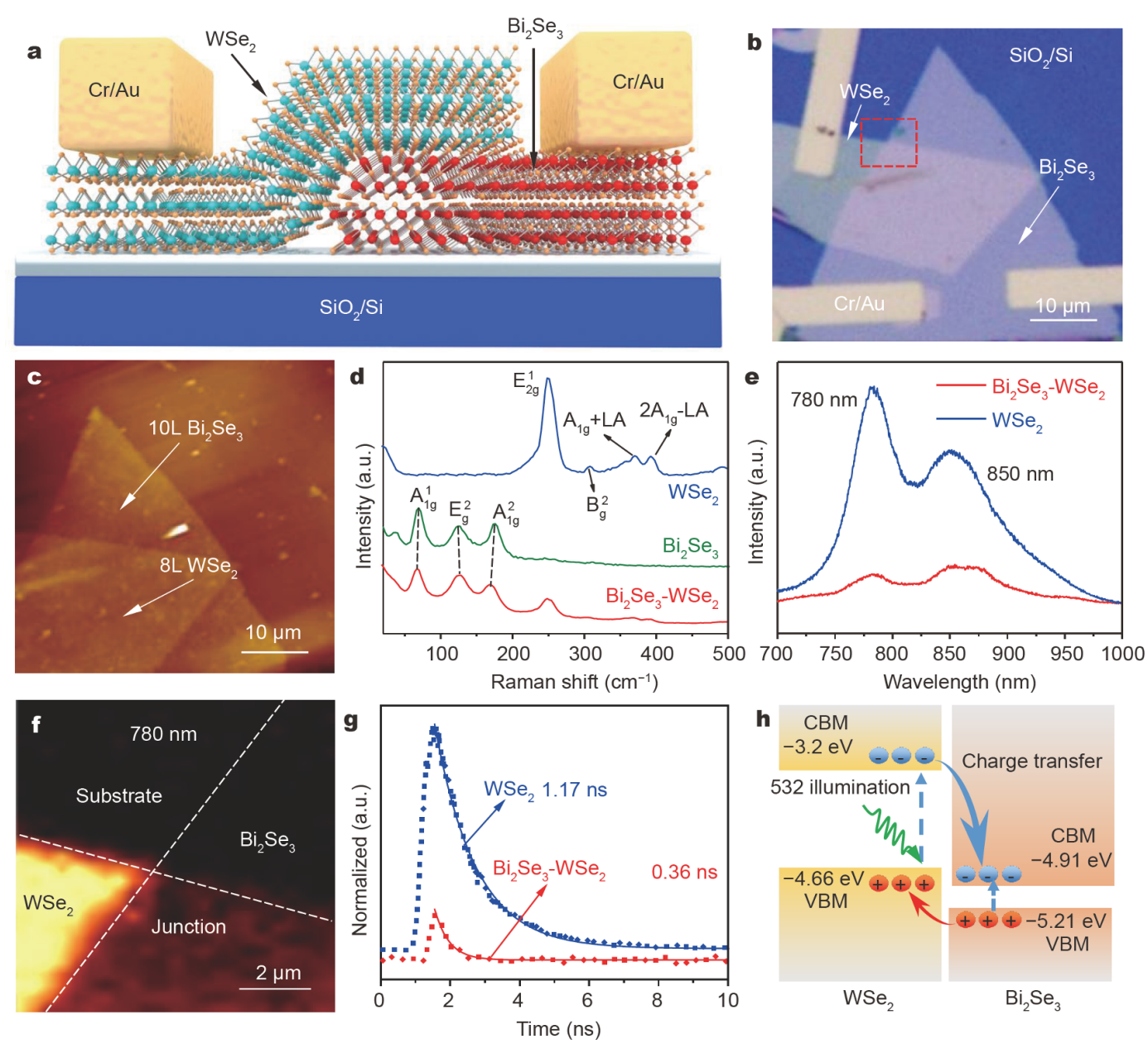

Figure 1 Device structure and optical characterizations. (a) 3D schematic of the $\mathrm{Bi}_{2} \mathrm{Se}_{3} / \mathrm{WSe}_{2}$ heterostructure. (b, c) Optical image and AFM of the $\mathrm{Bi}_{2} \mathrm{Se}_{3} / \mathrm{WSe}_{2}$ heterostructure. (d) Raman spectra of the pristine $\mathrm{Bi}_{2} \mathrm{Se}_{3}, \mathrm{WSe}_{2}$ and the heterostructure. (e) PL spectra measured for WSe $e_{2}$ and the heterostructure. (f) PL mapping of the region surrounded by red dashed lines in Fig. 1b. The dark portion from the overlapped region suggests strong PL quenching. (g) Time-dependence PL spectra of the isolated WSe $e_{2}$ and $\mathrm{Bi}_{2} \mathrm{Se}_{3} / \mathrm{WSe}_{2}$. (h) Schematic diagram of the $\mathrm{Bi}_{2} \mathrm{Se}_{3} / \mathrm{WSe}_{2}$ heterostructure band structure and photoexcitation.

respectively, indicating the Fermi level $\left(E_{\mathrm{F}}\right)$ of $\mathrm{WSe}_{2}$ and $\mathrm{Bi}_{2} \mathrm{Se}_{3}$ are -3.86 and $-4.61 \mathrm{eV}$ with respect to the vacuum level. The difference between $E_{\mathrm{F}}$ and valence band maximum $\left(E_{\mathrm{VBM}}\right)$ was obtained by linearly extrapolating the low binding energy region of the spectra to the baseline (Fig. S2a, c) [26,27]. The $E_{\mathrm{VBM}}$ for $\mathrm{WSe}_{2}$ and $\mathrm{Bi}_{2} \mathrm{Se}_{3}$ were then calculated to be -4.66 and $-5.21 \mathrm{eV}$, respectively. The bandgap values of $\mathrm{Bi}_{2} \mathrm{Se}_{3}(\sim 0.3 \mathrm{eV})$ [28-30] and $\mathrm{WSe}_{2}$ $(\sim 1.46 \mathrm{eV}$ for multilayers) [20,31,32] were further obtained from previous reports and PL spectrum (Fig. 1g), and accordingly the band alignment diagrams of the $\mathrm{Bi}_{2} \mathrm{Se}_{3} / \mathrm{WSe}_{2}$ heterostructure was established as Fig. S2e and Fig. 1h. One can observe that the maximum valence band of $\mathrm{WSe}_{2}$ is above the minimum conduction band of $\mathrm{Bi}_{2} \mathrm{Se}_{3}$, forming a broken-gap band alignment heterojunction $[20,22]$.
Raman spectra of $\mathrm{Bi}_{2} \mathrm{Se}_{3}, \mathrm{WSe}_{2}$ and the $\mathrm{Bi}_{2} \mathrm{Se}_{3} / \mathrm{WSe}_{2}$ heterostructure are displayed in Fig. 1d. The individual $\mathrm{Bi}_{2} \mathrm{Se}_{3}$ flake demonstrates three distinct Raman peak positions at 69,124 , and $175 \mathrm{~cm}^{-1}$, corresponding to the $A_{1 g}^{1}$, $\mathrm{E}_{\mathrm{g}}^{2}$, and $\mathrm{A}_{\mathrm{lg}}^{2}$ modes, respectively, which are in accordance with the previous reports [25]. The pristine $\mathrm{WSe}_{2}$ flake shows four obvious Raman peaks at 250, 307, 370, and $392 \mathrm{~cm}^{-1}$, assigned to the $\mathrm{E}_{2 \mathrm{~g}}^{1}, \mathrm{~B}_{\mathrm{g}}^{2}, \mathrm{~A}_{1 \mathrm{~g}}+\mathrm{LA}$, and $2 \mathrm{~A}_{1 \mathrm{~g}} \mathrm{LA}$ modes as reported by others [33], respectively. In the overlapped $\mathrm{Bi}_{2} \mathrm{Se}_{3} / \mathrm{WSe}_{2}$ heterostructure region, the characteristic Raman peaks of both $\mathrm{Bi}_{2} \mathrm{Se}_{3}$ and $\mathrm{WSe}_{2}$ can be distinctly observed, indicating the good quality of the heterostructure. Notably, in the overlapped region, the intensities of the Raman peaks of $\mathrm{WSe}_{2}$ are obviously reduced despite that the $\mathrm{WSe}_{2}$ flake is located on top of $\mathrm{Bi}_{2} \mathrm{Se}_{3}$, and meanwhile the Raman peak positions of the 
$\mathrm{Bi}_{2} \mathrm{Se}_{3}$ obviously shift to the negative position. This suggests strong interfacial coupling may occur within the heterostructure $[33,34]$.

In order to further confirm the interfacial coupling effect, room temperature PL spectra and mapping were collected from the $\mathrm{Bi}_{2} \mathrm{Se}_{3} / \mathrm{WSe}_{2}$ heterostructure (Fig. 1e, f). The results indicate that the $\mathrm{WSe}_{2}$ flake exhibits a strong PL emission peak at $780 \mathrm{~nm}(1.58 \mathrm{eV})$ and a weak emission peak at $850 \mathrm{~nm}(1.46 \mathrm{eV})$, corresponding to the recombination of $\mathrm{A}$ exciton peak and indirect transition $\mathrm{I}$ peak, respectively [35-37]. The $\mathrm{Bi}_{2} \mathrm{Se}_{3} / \mathrm{WSe}_{2}$ heterostructure region demonstrates an apparent $\mathrm{PL}$ quenching effect, as the PL intensity of $\mathrm{WSe}_{2}$ decays to $12 \%$ of the pristine (Fig. 1e). This suggests the photoexcited carriers are primarily transferred between the $\mathrm{WSe} e_{2}$ and $\mathrm{Bi}_{2} \mathrm{Se}_{3}$ interface, rather than emitting from the individual $\mathrm{WSe}_{2}$ band edges $[38,39]$. The interfacial carrier transfer behaviors were further studied by using the time-resolved PL spectra upon $375 \mathrm{~nm}$ pulse laser excitation [40,41]. As shown in Fig. 1g, the transient PL decay curves were fitted by a single exponential decay function $\left(y(\tau)=y_{0}+A \exp -\frac{x-x_{0}}{\tau}\right)$. In the heterostructure region, one can observe that the PL transient from $\mathrm{WSe}_{2}$ ( $\tau_{\text {heterojuction }}=0.36 \mathrm{~ns}$ ) is significantly reduced as compared with the pristine $\mathrm{WSe}_{2}\left(\tau_{\mathrm{WSe}_{2}}=1.17 \mathrm{~ns}\right)$. This further confirms the existence of efficient interfacial carrier transfer at $\mathrm{Bi}_{2} \mathrm{Se}_{3} / \mathrm{WSe}_{2}$ interface $[20,27,40]$. Accordingly, the electronic band alignment of the $\mathrm{Bi}_{2} \mathrm{Se}_{3} / \mathrm{WSe}_{2}$ heterostructure is schematically illuminated in Fig. $1 \mathrm{~h}$. We found that the photo-induced carriers (electrons) in the $\mathrm{WSe}_{2}$ tend to transfer to the low-energy states in $\mathrm{Bi}_{2} \mathrm{Se}_{3}$, instead of forming excitons, resulting in the significant $\mathrm{PL}$ quenching effect of the heterostructure.

Fig. 2a displays the schematic diagram for the electrical characterizations. The tests were performed on the $\mathrm{Bi}_{2} \mathrm{Se}_{3} /$
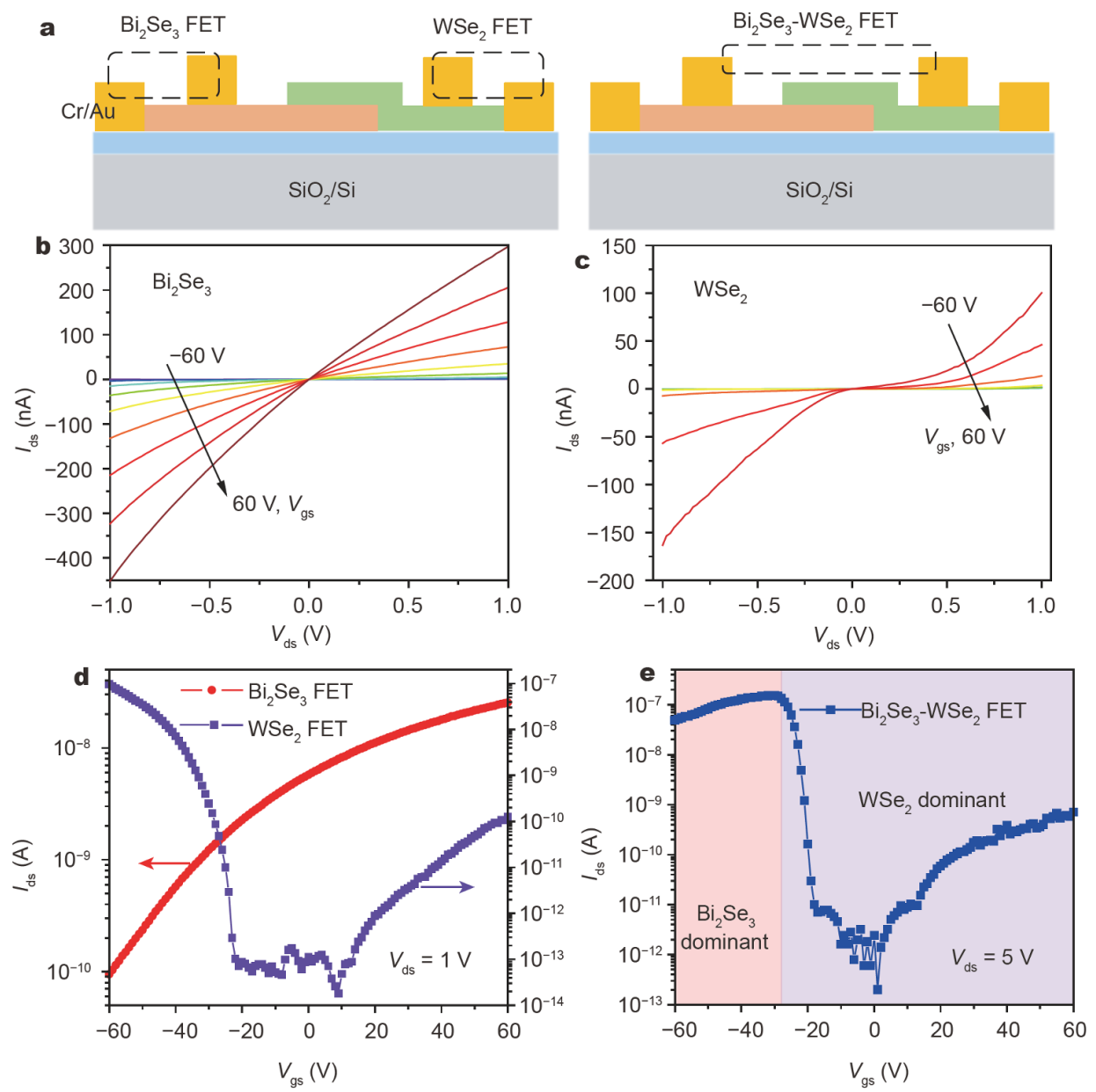

Figure 2 Electrical characteristics of the $\mathrm{Bi}_{2} \mathrm{Se}_{3} / \mathrm{WSe}_{2}$ heterostructure. (a) The schematic diagram of the $\mathrm{Bi}_{2} \mathrm{Se}_{3} / \mathrm{WSe}_{2}$ heterostructure for electrical measurements. (b, c) Output characteristics of $\mathrm{Bi}_{2} \mathrm{Se}_{3}$ and $\mathrm{WSe} e_{2}$, respectively. (d, e) Transfer characteristics of the $\mathrm{Bi}_{2} \mathrm{Se}_{3} / \mathrm{WSe}_{2}$ heterostructure. 
$\mathrm{WSe}_{2}$ heterostructure region as well as the individual $\mathrm{Bi}_{2} \mathrm{Se}_{3}$ and $\mathrm{WSe}_{2}$ regions. The output characteristic curves of individual $\mathrm{Bi}_{2} \mathrm{Se}_{3}$ exhibit a linear behavior (Fig. 2b), indicating the good Ohmic contacts between $\mathrm{Bi}_{2} \mathrm{Se}_{3}$ and the electrodes. For the individual $\mathrm{WSe}_{2}$ device, the sublinear output characteristic is observed (Fig. 2c), indicating the formation of Schottky barrier at the contact interface of $\mathrm{WSe}_{2}$ and the electrodes. This can be attributed to the difference of WF between $\mathrm{WSe}_{2}\left(\mathrm{WF}_{\mathrm{WS}_{2}} \approx\right.$ $3.86 \mathrm{eV})$ and $\mathrm{Cr}\left(\mathrm{WF}_{\mathrm{Cr}} \approx 4.6 \mathrm{eV}\right)$. The transfer characteristic curves in Fig. $1 \mathrm{~d}$ indicate $\mathrm{Bi}_{2} \mathrm{Se}_{3}$ is an n-type semiconductor, while $\mathrm{WSe}_{2}$ has a p-terminal dominated ambipolar characteristic, which is consistent with previous literatures $[25,42]$. The transfer characteristics of the heterojunction region are plotted in Fig. 2e. The transfer curve can be divided into three regions. In region I (gate voltage $V_{\mathrm{gs}}<-30 \mathrm{~V}$ ), the drain current $\left(I_{\mathrm{ds}}\right)$ decreases as the $V_{\mathrm{gs}}$ increases negatively, indicating the depletion of electrons in $\mathrm{Bi}_{2} \mathrm{Se}_{3}$ channel. In region II $\left(-30 \mathrm{~V}<V_{\mathrm{gs}}<0 \mathrm{~V}\right)$, the gate bias gradually depletes the WSe $e_{2}$ carriers, and the $I_{\mathrm{ds}}$ is controlled by the $\mathrm{Bi}_{2} \mathrm{Se}_{3}$ and non-overlapped $\mathrm{WSe}_{2}$ transistor, leading to the rapid decrease of $I_{\mathrm{ds}}$ in the depleted $\mathrm{WSe}_{2}$. In region III $\left(V_{\mathrm{gs}}>\right.$ $0 \mathrm{~V}$ ), where the $\mathrm{WSe}_{2}$ reaches the ambipolar transition point, the $I_{\mathrm{ds}}$ increases on account of the increasing conductance of $\mathrm{WSe}_{2}$, which dominates the electrical characteristics of the whole junction in this region.

The transport characteristics of the heterostructure device were further studied in detail to understand the interaction in the overlapped heterojunction region. Note that all results are acquired by applying a drain voltage $\left(V_{\mathrm{ds}}\right)$ on $\mathrm{p}-\mathrm{WSe}_{2}$ with $\mathrm{n}-\mathrm{Bi}_{2} \mathrm{Se}_{3}$ being ground. As demonstrated in Fig. 3a, an obvious forward diode behavior with a rectification ratio over $10^{3}$ and ultralow reverse current below picoampere are observed in the $\mathrm{Bi}_{2} \mathrm{Se}_{3} /$ $\mathrm{WSe}_{2}$ heterostructure. However, when the current-voltage curve is plotted in a log-log form (Fig. 3b), we observe two distinct linear regions with slope greater than 1 in the forward bias, which simply implies a tunneling effect [33]. As indicated by the band diagram shown in Fig. S2e, a broken-gap band alignment is established in the heterostructure, and thus the electrons can transport from $\mathrm{Bi}_{2} \mathrm{Se}_{3}$ to $\mathrm{WSe}_{2}$ via the tunneling effect, giving rise to the sharp increase of forward current [43]. We further modeled the forward current-transport across the heterostructure by using the direct tunneling (DT) at lower $V_{\mathrm{ds}}$ and the Fowler-Nordheim tunneling (FNT) at higher $V_{\mathrm{ds}}$. The DT and FNT models can be described as the following expressions $[19,33]$ :

$$
\begin{aligned}
& I_{\mathrm{DT}} \propto V \exp \left(-\frac{4 \pi d \sqrt{2 m^{*} \varphi}}{h}\right), \\
& I_{\mathrm{FNT}} \propto V^{2} \exp \left(-\frac{8 \pi d \sqrt{2 m^{*} \varphi^{3}}}{3 h e V}\right),
\end{aligned}
$$

where $V$ is the applied bias voltage, $m^{*}, h, e, d$ and $\varphi$ are
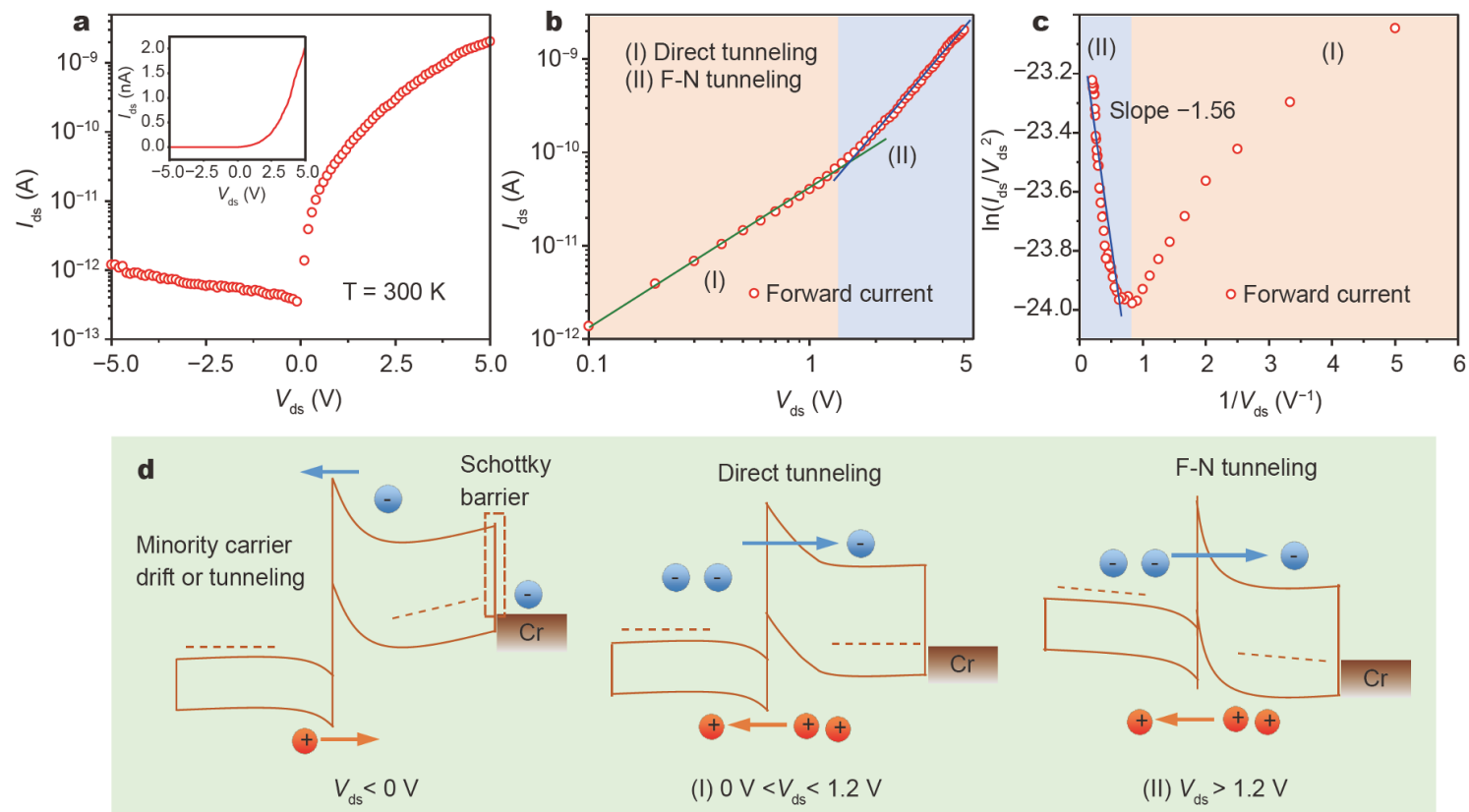

Figure 3 Tunneling behavior of the $\mathrm{Bi}_{2} \mathrm{Se}_{3} / \mathrm{WSe} e_{2}$ heterostructure. (a) $I_{\mathrm{ds}}-V_{\mathrm{ds}}$ curve of the heterostructure. (b) $I_{\mathrm{ds}}-V_{\mathrm{ds}}$ characteristic of the heterostructure in double-log scale. (c) Fowler-Nordheim fitting of forward current. (d) Band diagrams of the heterostructure at different bias voltages. 
the effective mass of the carrier, Planck's constant, element charge, tunneling thickness and tunneling barrier height, respectively. As shown in Fig. $3 \mathrm{c}$ and Fig. S3, the fitted plots exhibit a good linear relationship, indicating the well-feasibility of the above equations. A tunneling barrier of $\varphi \approx 1.2 \mathrm{eV}$ in the FNT was finally extracted from the linear region in Fig. 3b. Similar tunneling operations are observed in other two $\mathrm{Bi}_{2} \mathrm{Se}_{3} / \mathrm{WSe}_{2}$ devices (Fig. S4), which further confirm they are indeed the case. Based on the above analysis, a possible carrier transport mechanism for the $\mathrm{Bi}_{2} \mathrm{Se}_{3} / \mathrm{WSe}_{2}$ heterostructure is described in Fig. $3 \mathrm{~d}$. Under the reverse bias voltage $\left(V_{\mathrm{ds}}<0 \mathrm{~V}\right)$, the electrons/holes in $\mathrm{Bi}_{2} \mathrm{Se}_{3} / \mathrm{WSe}_{2}$ are blocked by the external electric field and the minority carriers of electrons/holes in the $\mathrm{WSe}_{2} / \mathrm{Bi}_{2} \mathrm{Se}_{3}$ may drift or tunnel to the conduction/ valence band of $\mathrm{Bi}_{2} \mathrm{Se}_{3} / \mathrm{WSe}_{2}$. In spite of such drifting or tunneling effect, the existence of a large Schottky barrier between $\mathrm{WSe}_{2}$ and contact electrode further hinders the effective carrier transport and results in the ultralow reverse current (below picoampere). When a small forward voltage is applied $\left(0<V_{\mathrm{ds}}<1.2 \mathrm{~V}\right)$, the high triangular tunneling barrier in the heterostructure plays a dominant role for the charge transfer with DT. Moreover, the barrier would be narrower and more triangular at larger bias $\left(V_{\mathrm{ds}}>1.2 \mathrm{~V}\right)$, resulting in the continuous generation of FNT and dramatic increase of the forward current. In general, carriers can transit across the barrier by means of tunneling or thermionic emission (diffusion) [20,43]. The tunneling-based carrier transport is independent of the temperature, while the thermionic emission-dominated transport significantly depends on the temperature. To distinguish the dominant carrier transport mechanism, the temperature-dependent electrical characteristics were further studied (Fig. S5). As expected, the FNT behavior occurs in the temperature range of 100-300 K, which confirms that the tunneling effect dominates the carrier transport in the heterostructure. In addition, we estimated the mean free path of electron and width of the depletion in $\mathrm{WSe}_{2}$ to be 62.5 and $4.2 \mathrm{~nm}$, respectively. The former is much larger than the latter, indicating that the carrier transport tends to be tunneling rather than thermionic emission. What is more, the high doping concentration of $\mathrm{WSe}_{2}\left(N_{\mathrm{d}} \approx 2.6 \times 10^{18} \mathrm{~cm}^{-3}\right)$ allows for a large tunneling probability. This tunneling mechanism is different from the reported metal-semiconductor interface tunneling effect, the latter of which is dominated by the thermionic FNT, such as $\mathrm{Pd} / \mathrm{MoS}_{2}$ [44], $\mathrm{Pd} / \mathrm{WSe}_{2} /$ $\mathrm{SnSe}_{2}$ [45] and V-doped $\mathrm{WSe}_{2} / \mathrm{SnSe}_{2}$ [46].

Considering the complementary bandgaps of $\mathrm{WSe}_{2}$ $(1.46 \mathrm{eV})$ and $\mathrm{Bi}_{2} \mathrm{Se}_{3}(0.3 \mathrm{eV})$, their heterostructures may exhibit excellent photoresponse performances in both visible and near-infrared regions [20,25]. Thus, we further evaluated the potential applications of the $\mathrm{Bi}_{2} \mathrm{Se}_{3} /$ $\mathrm{WSe}_{2}$ tunneling heterostructure for visible and near-infrared photodetectors. Fig. $4 \mathrm{a}, \mathrm{b}$ present the output characteristics of the obtained tunneling device under 532 and $1456 \mathrm{~nm}$ laser illumination with different power densities, respectively. The currents in both forward and reverse biases showed significant increases with the increase of power density under laser illumination. In addition, we found that the $I_{\mathrm{ds}}-V_{\mathrm{ds}}$ characteristics under 532 and $1456 \mathrm{~nm}$ laser illumination could be modeled by the DT mechanism with perfect linear relationship between $\ln \left(I_{\mathrm{ds}} / V_{\mathrm{ds}}{ }^{2}\right)$ and $\ln \left(1 / V_{\mathrm{ds}}{ }^{2}\right)$ at reverse biases voltage (Fig. $4 \mathrm{c}$ and Fig. S6). This indicates that the photocarriers generated in $\mathrm{Bi}_{2} \mathrm{Se}_{3}$ and $\mathrm{WSe}_{2}$ are dominated by the tunneling mechanism, leading to the formation of obvious photocurrent with the help of the external electric field. Fig. $4 \mathrm{e}, \mathrm{f}$ present the schematics of visible and near-infrared photoresponse at reverse bias voltage. Under $532 \mathrm{~nm}$ laser illumination, both $\mathrm{Bi}_{2} \mathrm{Se}_{3}$ and $\mathrm{WSe}_{2}$ produce photon-generated electron-hole pairs. The barrier height of heterojunction region in light state becomes smaller than that in dark state, consequently forming the DT. Under the illumination of $1456 \mathrm{~nm}$ near-infrared light (below the bandgap of $\mathrm{WSe}_{2}$ ), the carriers are generated only in $\mathrm{Bi}_{2} \mathrm{Se}_{3}$. The photo-generated electrons would enter the circuit, while the photo-generated holes would accumulate at the interface and tunnel into the valence band of $\mathrm{WSe}_{2}$. Furthermore, the light on/off ratio $\left(I_{\mathrm{ph}} / I_{\text {dark }}\right)$ was obtained by comparing the drain current under laser illumination and dark state. The dependence of light on/off ratio on the bias voltage is shown in Fig. 4d. At reverse bias voltage, the $I_{\mathrm{ph}} / I_{\text {dark }}$ ratio increases dramatically at lower $\left|V_{\mathrm{ds}}\right|$ because of the increase of photocurrent with DT effect (Fig. S6) and maintaining dark current, whereas the $I_{\mathrm{ph}} / I_{\text {dark }}$ ratio hardly increases due to non-negligible electron tunneling at higher $\left|V_{\mathrm{ds}}\right|$ in dark. At forward bias, the decrease of $I_{\mathrm{ph}} / I_{\text {dark }}$ ratio is mainly attributed to the exponential increasing in dark current with FNT effect. Consequently, we obtained the maximum $I_{\mathrm{ph}} / I_{\mathrm{dark}}$ of $\sim 7.5 \times 10^{5}$ for $532 \mathrm{~nm} @ 73.06 \mathrm{~mW} \mathrm{~cm}^{-2}$ and $3.5 \times 10^{4}$ for $1456 \mathrm{~nm} @ 142.93 \mathrm{~mW} \mathrm{~cm}^{-2}$ in the range of reverse bias voltage. To the best of our knowledge, this on/off ratio value is far superior to the reported generic $\mathrm{p}-\mathrm{n}$ junctions with gate regulation [47], low ambient temperature [9] or ferroelectric field suppression [48], attributed to the ultralow dark current $(<\mathrm{pA})$ at the reverse bias.

In order to further understand the performance of the $\mathrm{Bi}_{2} \mathrm{Se}_{3} / \mathrm{WSe}_{2}$ tunneling heterostructure visible and near- 

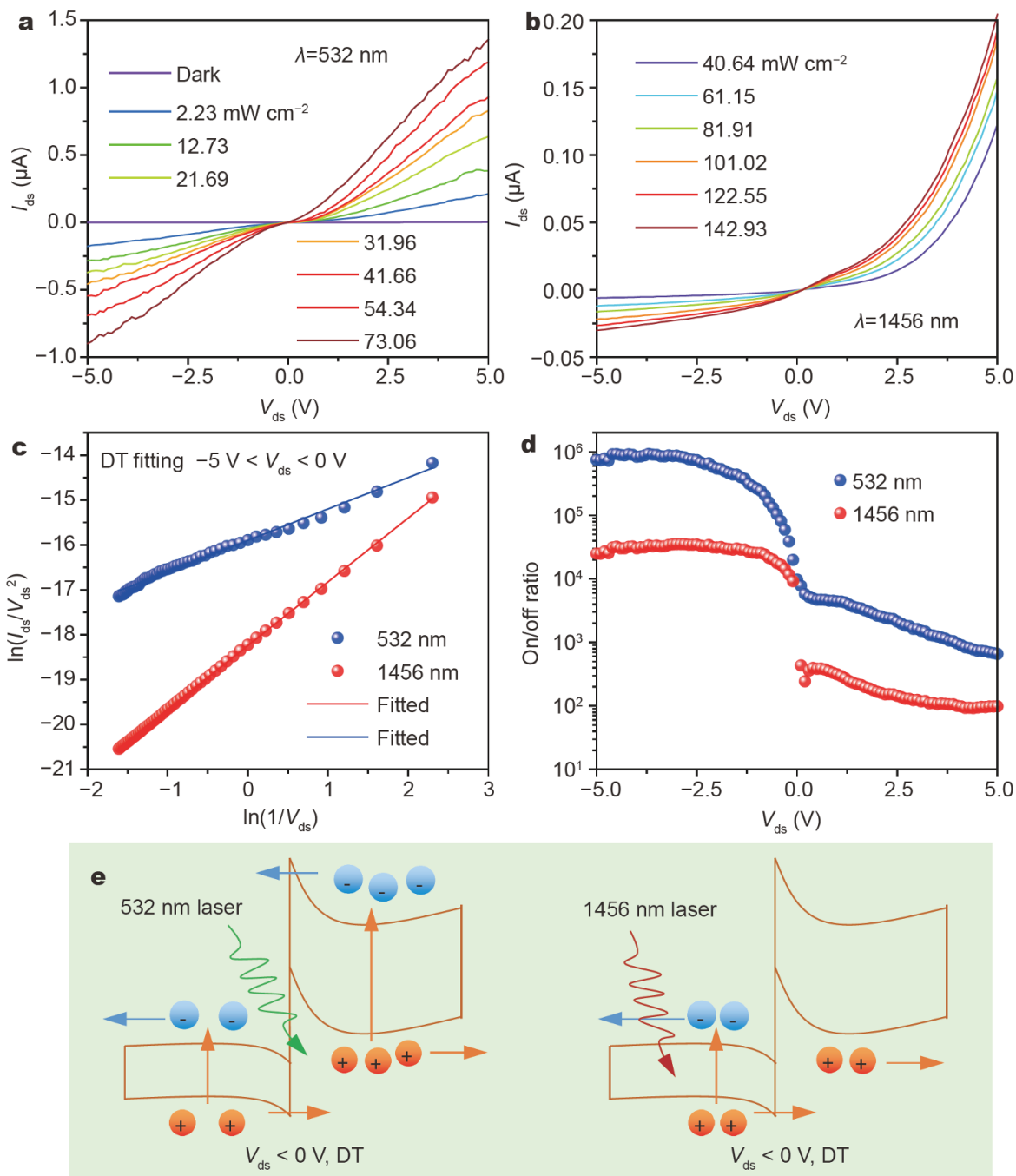

Figure 4 Photoelectric characteristics of the tunneling heterostructure. (a, b) $I_{\mathrm{ds}}-V_{\mathrm{ds}}$ curves of the heterostructure under 532 and 1456 nm laser illumination with various power densities, respectively. (c) DT fitting of the $\mathrm{Bi}_{2} \mathrm{Se}_{3} / \mathrm{WSe}_{2}$ heterostructure at reverse bias voltage. (d) Light on/off ratio as a function of bias voltage under $532 \mathrm{~nm} @ 73.06 \mathrm{~mW} \mathrm{~cm}^{-2}$ and $1456 \mathrm{~nm} @ 142.93 \mathrm{~mW} \mathrm{~cm}^{-2}$. (e, f) Energy band diagram of the Bi $\mathrm{Se}_{3} / \mathrm{WSe}_{2}$ heterostructure at reverse bias voltage.

infrared photodetector, we have analyzed the data systematically. The responsivity $(R)$ is a key parameter to evaluate the performance of photodetectors and would be calculated by the equation of $R=I_{\mathrm{ph}} / P S$, where $I_{\mathrm{ph}}, P$ and $S$ refer to the photocurrent, incident light power density and the channel area of the $\mathrm{Bi}_{2} \mathrm{Se}_{3} / \mathrm{WSe}_{2}$ device, respectively. Fig. $5 \mathrm{a}$ presents the dependence of responsivity on the incident power density for 532 and $1456 \mathrm{~nm}$ wavelength at $V_{\mathrm{ds}}= \pm 5 \mathrm{~V}$. Obviously, the responsivity can be optimized by varying the incident power densities and bias voltage. For visible light of $532 \mathrm{~nm}$, the responsivity can reach up to $94.26 \mathrm{~A} \mathrm{~W}^{-1}$ at the power density of $2.23 \mathrm{~mW} \mathrm{~cm}^{-2}$ at $V_{\mathrm{ds}}=5 \mathrm{~V}$, which is highly comparable to the highest responsivity values that have been reported for tunneling heterostructures $[20,22]$. The near-infrared responsivity is up to $3 \mathrm{~A} \mathrm{~W}^{-1}$, which is $\sim 3 \times 10^{3}$ times higher than that of the previously reported InSe/AsP near-infrared photodetector [22]. To evaluate the sensitivity of the $\mathrm{Bi}_{2} \mathrm{Se}_{3} / \mathrm{WSe}_{2}$ heterostructure photodetector, the noise current density $\left(i_{\mathrm{n}}{ }^{2}\right)$ was measured under the dark and bias conditions. As shown in Fig. 5b, benefiting from the inhibition of dark current by Schottky barrier between $\mathrm{WSe}_{2}$ and $\mathrm{Cr}$ electrodes, the current noise at reverse bias voltage was improved significantly with respect to that at forward bias voltage, but the frequency $(f)$ dependence results are similar. In the range of $f<100 \mathrm{~Hz}$, 

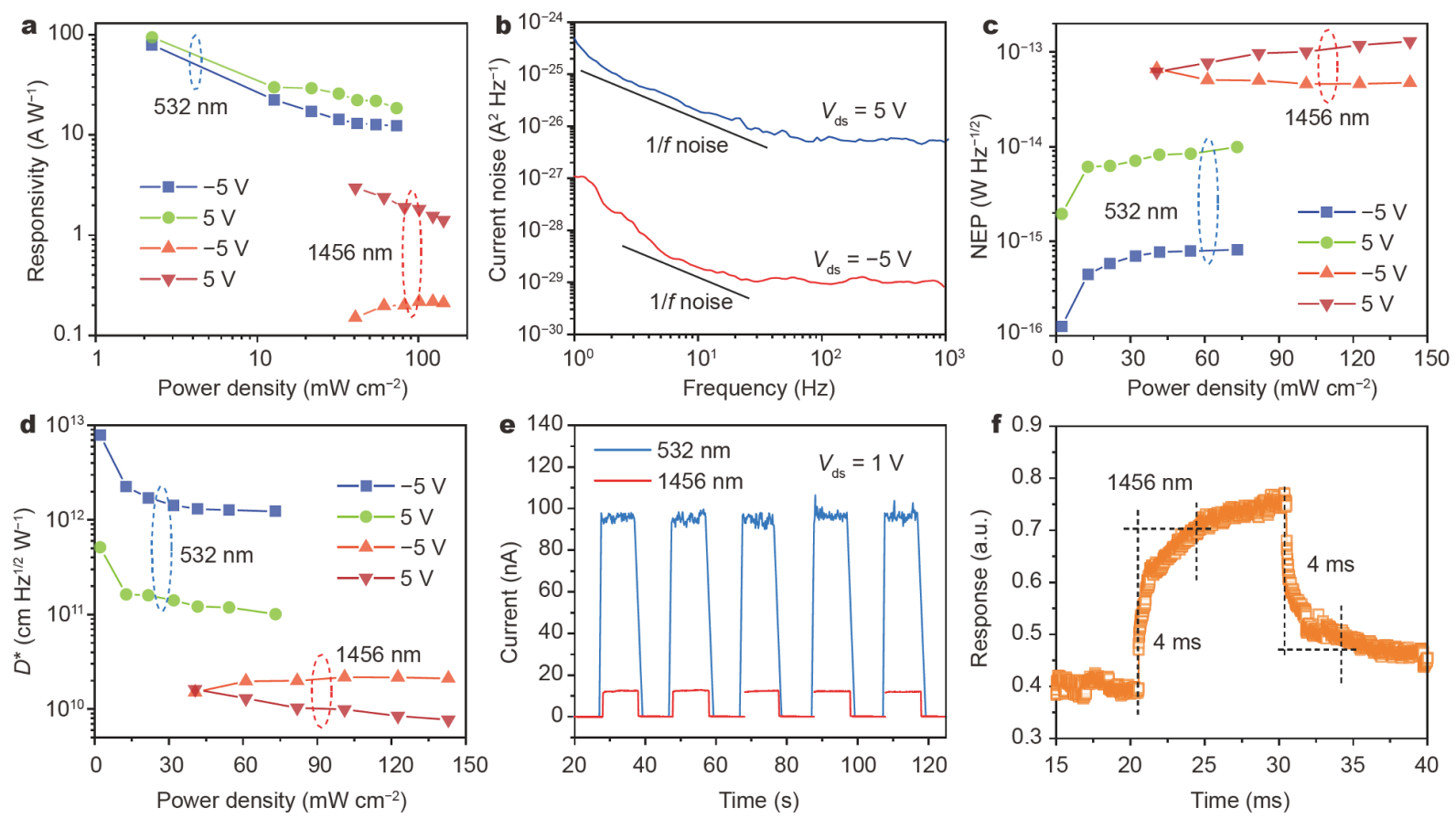

Figure 5 Photoresponse performance of the heterostructure at wavelengths of 532 and $1456 \mathrm{~nm}$. (a) Incident power density dependence of responsivity at different $V_{\mathrm{ds}}$. (b) Spectra of current noises at $V_{\mathrm{ds}}= \pm 5 \mathrm{~V}$. (c) NEP as a function of power density. (d) Specific detectivity versus the incident power density. (e) Time-resolved photoresponse of the heterostructure under 532 and 1456 nm laser illumination. (f) Response time curve of the heterostructure under $1456 \mathrm{~nm}$ illumination.

the $1 / f$-noise component was observed, which reveals that the noise behavior of the $\mathrm{Bi}_{2} \mathrm{Se}_{3} / \mathrm{WSe}_{2}$ heterostructure photodetector is dominated by the $1 / f$-noise. The $1 / f$ noise arises from the fluctuations of local electronic states caused by the disorder or defects [49]. While in the region of $f>100 \mathrm{~Hz}$, the generation-recombination (g-r) noise which results from the carrier density fluctuation caused by the charge trapping-detrapping centers becomes dominant [49]. Specific detectivity $\left(D^{*}\right)$ is identified as another key parameter of merit to evaluate the sensitivity of a photodetector and calculated as $D^{*}=(S \Delta f)^{1 / 2} / \mathrm{NEP}$, in which $\Delta f$ refers to the electrical bandwidth and NEP refers to the noise equivalent power. The NEP would be calculated by the equation of $\mathrm{NEP}=\left(\overline{i_{n}^{2}}\right)^{1 / 2} / R$, where $\left(\overline{i_{n}^{2}}\right)^{1 / 2}$ refers to the root mean square of current noise. The $\left(\overline{i_{n}^{2}}\right)^{1 / 2}$ are calculated to be $1.84 \times 10^{-13}$ and $1.01 \times 10^{-14} \mathrm{~A} \mathrm{~Hz}^{-1}$ at $V_{\mathrm{ds}}=5$ and $-5 \mathrm{~V}$, respectively. The current noise at reverse bias voltage is lower than that at forward bias, which is attributed to the potential barrier at the heterojunction region and the Schottky potential at the interface of $\mathrm{WSe}_{2}$ flake and metal electrodes. Correspondingly, the NEP values under different incident powerdensities at $V_{\mathrm{ds}}= \pm 5 \mathrm{~V}$ were calculated and shown in Fig. 5c. Accordingly, the incident power density-dependent specific detectivity at $V_{\mathrm{ds}}= \pm 5 \mathrm{~V}$ is presented in Fig. 5d. Optimal specific detectivities of up to $7.9 \times 10^{12}$ and $2.2 \times 10^{10}$ Jones were respectively obtained for 532 and $1456 \mathrm{~nm}$ wavelength, which is again far superior to most of the reported photodetectors [50].

Apart from the responsivity and specific detectivity, response rate is also an important parameter for photodetectors. As shown in Fig. 5e, the heterostructure exhibits well-reproducible photoswitching characteristics under 532 and $1456 \mathrm{~nm}$ laser modulations at $V_{\mathrm{ds}}=1 \mathrm{~V}$. In order to investigate the working bandwidth of the $\mathrm{Bi}_{2} \mathrm{Se}_{3} /$ $\mathrm{WSe}_{2}$ photodetector, the pulsed 532-nm laser with frequency varying from 1 to $400 \mathrm{~Hz}$ and a digital oscilloscope was utilized to determine the variation of photocurrent. Fig. S7a shows a representative temporal response of the photodetector at the frequency of $100 \mathrm{~Hz}$. It is worth noting that the $\mathrm{Bi}_{2} \mathrm{Se}_{3} / \mathrm{WSe}_{2}$ photodetector presents a good long-term stability and reproducibility in the range of $1-400 \mathrm{~Hz}$. By plotting the relationship between the relative balance $\left(I_{\max }-I_{\min }\right) / I_{\max }$ and the pulsed frequency, as shown in Fig. S7b, we could observe the $3 \mathrm{~dB}$ bandwidth of $\sim 100 \mathrm{~Hz}$. Fig. S7c and Fig. 5f show a 
Table 1 Photoelectric performance comparison of this work with similar vdWH photodetectors previously reported

\begin{tabular}{|c|c|c|c|c|c|c|c|}
\hline Device & $\begin{array}{l}\text { Wavelength } \\
(\mathrm{nm})\end{array}$ & Bias (V) & On/off ratio & $\begin{array}{l}\text { Responsivity } \\
\left(\mathrm{A} \mathrm{W}^{-1}\right)\end{array}$ & $\begin{array}{l}\text { Detectivity } \\
\text { (Jones) }\end{array}$ & Response rate & Ref. \\
\hline $22 \mathrm{~nm} \mathrm{BP}-12 \mathrm{~nm} \mathrm{MoS}$ & 532 & $V_{\mathrm{ds}}=3$ & $10^{4}$ & 22.3 & $3.1 \times 10^{11}$ & - & {$[15]$} \\
\hline $1.5 \mathrm{~nm} \mathrm{WSe} \mathrm{Wm}_{2}-4 \mathrm{~nm} \mathrm{SnS}_{2}$ & 550 & $\begin{array}{c}V_{\mathrm{ds}}=-1 \\
V_{\mathrm{gs}}=-20\end{array}$ & $8.2 \times 10^{6}$ & 244 & $1.29 \times 10^{13}$ & $13 / 24 \mathrm{~ms}$ & {$[20]$} \\
\hline $11.5 \mathrm{~nm}$ AsP-10 nm InSe & 520 & $V_{\mathrm{ds}}=2$ & $10^{7}$ & $\sim 1$ & $\sim 1 \times 10^{12}$ & $217 / 89 \mu \mathrm{s}$ & {$[22]$} \\
\hline 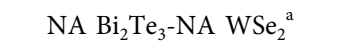 & 633 & $V_{\mathrm{ds}}=1$ & - & 20.5 & - & $180 / 210 \mu \mathrm{s}$ & {$[52]$} \\
\hline $10.5 \mathrm{~nm} \mathrm{Bi}_{2} \mathrm{Se}_{3}-5.6 \mathrm{~nm} \mathrm{WSe}_{2}$ & 532 & $V_{\mathrm{ds}}=-5$ & $7.5 \times 10^{5}$ & 94.26 & $7.9 \times 10^{12}$ & $1.5 / 0.11 \mathrm{~ms}$ & This work \\
\hline $22 \mathrm{~nm} \mathrm{BP}-12 \mathrm{~nm} \mathrm{MoS} 2$ & 1550 & $V_{\mathrm{ds}}=3$ & $\sim 10$ & 0.153 & $2.13 \times 10^{9}$ & $15 \mu \mathrm{s}$ & {$[15]$} \\
\hline $11.5 \mathrm{~nm}$ AsP-10 nm InSe & 1550 & $V_{\mathrm{ds}}=2$ & $2.5 \times 10^{3}$ & $\sim 10^{-3}$ & $2.74 \times 10^{9}$ & - & {$[22]$} \\
\hline $4 \mathrm{~nm} \mathrm{Bi}_{2} \mathrm{Te}_{3}-15 \mathrm{~nm} \mathrm{WS}$ & 1550 & $V_{\mathrm{ds}}=1$ & - & $1.9 \times 10^{-3}$ & $2.7 \times 10^{7}$ & $20 \mathrm{~ms}$ & {$[51]$} \\
\hline $\mathrm{NA} \mathrm{Bi}_{2} \mathrm{Te}_{3}-\mathrm{NA} \mathrm{WSe}_{2}{ }^{\mathrm{a}}$ & 1550 & $V_{\mathrm{ds}}=1$ & - & $27 \times 10^{-3}$ & - & - & {$[52]$} \\
\hline $10.5 \mathrm{~nm} \mathrm{Bi} \mathrm{Se}_{3}-5.6 \mathrm{~nm} \mathrm{WSe} e_{2}$ & 1456 & $V_{\mathrm{ds}}=-5$ & $3.5 \times 10^{4}$ & 3 & $2.2 \times 10^{10}$ & $4 \mathrm{~ms}$ & This work \\
\hline
\end{tabular}

a) NA means that the thickness is not available.

temporal response in a single modulation cycle under 532 and $1456 \mathrm{~nm}$ laser illumination, respectively. For $532 \mathrm{~nm}$ photoresponse, the rise time of $\sim 1.5 \mathrm{~ms}$ and decay time of $\sim 0.11 \mathrm{~ms}$ are obtained by defining the time for the photocurrent rising from $10 \%$ to $90 \%$ and declining from $90 \%$ to $10 \%$, respectively. For $1456 \mathrm{~nm}$ light illumination, the rise and fall times are $4 \mathrm{~ms}$, which are slower than that at $532 \mathrm{~nm}$. The $1456 \mathrm{~nm}$ excitation wavelength exceeds the cutoff wavelength of $\mathrm{WSe}_{2}$, in which case only $\mathrm{Bi}_{2} \mathrm{Se}_{3}$ can absorb photons to produce carriers. Therefore, the response under $1456 \mathrm{~nm}$ illumination is essentially a $\mathrm{Bi}_{2} \mathrm{Se}_{3}$ photodetector. The photoexcited electrons in $\mathrm{Bi}_{2} \mathrm{Se}_{3}$ would be captured by the trap state in $\mathrm{WSe}_{2}$ to generate a negative photogate. The photogating effect would prolong the life of minority carriers in $\mathrm{Bi}_{2} \mathrm{Se}_{3}$ and reduce the recombination rate of photo-generated carriers, resulting in a slower response rate as compared with under $532 \mathrm{~nm}$ illumination. We finally display the performance comparison of our tunnel devices and the recently reported similar vdWH photodetectors in Table 1. One can observe that the key parameters such as detectivity, responsivity, and response rate of our $\mathrm{Bi}_{2} \mathrm{Se}_{3} / \mathrm{WSe}_{2}$ heterostructure are highly comparable to the state-of-theart merits of the previously reported photodetection materials, suggesting our tunneling heterostructures are promising candidate for future practical optoelectronic applications from visible to the near-infrared region.

\section{CONCLUSIONS}

In conclusion, our study demonstrates the key tunneling behaviors of a type of bandgap-complemented vdWH for photodetection applications. The heterostructure is constructed by stacking wide-gap ( $\mathrm{WSe}_{2}$ ) and narrow-gap $\left(\mathrm{Bi}_{2} \mathrm{Se}_{3}\right)$ 2D semiconductor flakes. Our heterojunction design successfully introduces a large offset band alignment to suppress dark current $(<\mathrm{pA})$, which thus significantly improves the tunneling effect of photocarriers. As a result, the heterostructure device exhibits an excellent and well-balanced optoelectronic performance from the visible to the near-infrared region. The critical parameters of our tunneling heterostructures such as the specific detectivity of $7.9 \times 10^{12}$ and $2.2 \times 10^{10}$ Jones, responsivity of 94.26 and $3 \mathrm{~A} \mathrm{~W}^{-1}$ with a fast recovery rate of 0.11 and $4 \mathrm{~ms}$ are obtained at 532 and $1456 \mathrm{~nm}$, respectively, which are all standing for the new state-of-theart of similar photodetector devices. Our study paves a unique avenue to utilize the tunneling effect of the heterostructure to achieve high-performance and wide band photodetection form visible to near-infrared region.

Received 11 March 2020; accepted 12 April 2020;

published online 19 June 2020

1 Geim AK, Grigorieva IV. van der Waals heterostructures. Nature, 2013, 499: 419-425

2 Liu Y, Weiss NO, Duan X, et al. Van der Waals heterostructures and devices. Nat Rev Mater, 2016, 1: 16042

3 Koppens FHL, Mueller T, Avouris P, et al. Photodetectors based on graphene, other two-dimensional materials and hybrid systems. Nat Nanotech, 2014, 9: 780-793

4 Novoselov KS, Mishchenko A, Carvalho A, et al. 2D materials and van der Waals heterostructures. Science, 2016, 353: aac9439

5 Xia F, Wang H, Xiao D, et al. Two-dimensional material nanophotonics. Nat Photon, 2014, 8: 899-907

6 Lee $\mathrm{CH}$, Lee $\mathrm{GH}$, van der Zande AM, et al. Atomically thin p-n junctions with van der Waals heterointerfaces. Nat Nanotech, 2014, 9: 676-681

7 Wang F, Wang Z, Xu K, et al. Tunable GaTe- $\mathrm{MoS}_{2}$ van der Waals p-n junctions with novel optoelectronic performance. Nano Lett, 2015, 15: 7558-7566

8 Wang T, Andrews K, Bowman A, et al. High-performance $\mathrm{WSe}_{2}$ phototransistors with 2D/2D ohmic contacts. Nano Lett, 2018, 18: 
2766-2771

9 Li L, Han W, Pi L, et al. Emerging in-plane anisotropic twodimensional materials. InfoMat, 2019, 1: 54-73

10 Xie C, Mak C, Tao X, et al. Photodetectors based on two-dimensional layered materials beyond graphene. Adv Funct Mater, 2017, 27: 1603886

11 Long $\mathrm{M}$, Wang $\mathrm{Y}$, Wang $\mathrm{P}$, et al. Palladium diselenide longwavelength infrared photodetector with high sensitivity and stability. ACS Nano, 2019, 13: acsnano.8b09476

12 Wang Y, Liu E, Gao A, et al. Negative photoconductance in van der Waals heterostructure-based floating gate phototransistor. ACS Nano, 2018, 12: 9513-9520

13 Wang RY, Zhou FY, Lv L, et al. Modulation of the anisotropic electronic properties in $\mathrm{ReS}_{2}$ via ferroelectronic film. CCS Chem, 2019, 1: 268-277

14 Zhou X, Zhou N, Li C, et al. Vertical heterostructures based on $\mathrm{SnSe}_{2} / \mathrm{MoS}_{2}$ for high performance photodetectors. 2D Mater, 2017, 4: 025048

15 Ye L, Li H, Chen Z, et al. Near-infrared photodetector based on $\mathrm{MoS}_{2}$ /black phosphorus heterojunction. ACS Photonics, 2016, 3: 692-699

16 Wen $\mathrm{Y}$, Yin L, He P, et al. Integrated high-performance infrared phototransistor arrays composed of nonlayered $\mathrm{PbS}-\mathrm{MoS}_{2}$ heterostructures with edge contacts. Nano Lett, 2016, 16: 6437-6444

17 Cao R, Wang HD, Guo ZN, et al. Black phosphorous/indium selenide photoconductive detector for visible and near-infrared light with high sensitivity. Adv Opt Mater, 2019, 7: 1900020

18 Chu D, Lee YH, Kim EK. Selective control of electron and hole tunneling in 2D assembly. Sci Adv, 2017, 3: e1602726

19 Vu QA, Lee JH, Nguyen VL, et al. Tuning carrier tunneling in van der Waals heterostructures for ultrahigh detectivity. Nano Lett, 2017, 17: 453-459

20 Zhou X, $\mathrm{Hu} \mathrm{X}$, Zhou S, et al. Tunneling diode based on $\mathrm{WSe}_{2} / \mathrm{SnS}_{2}$ heterostructure incorporating high detectivity and responsivity. Adv Mater, 2018, 30: 1703286

21 Liu X, Qu D, Li HM, et al. Modulation of quantum tunneling via a vertical two-dimensional black phosphorus and molybdenum disulfide p-n junction. ACS Nano, 2017, 11: 9143-9150

22 Wu F, Xia $\mathrm{H}$, Sun $\mathrm{H}$, et al. AsP/InSe van der Waals tunneling heterojunctions with ultrahigh reverse rectification ratio and high photosensitivity. Adv Funct Mater, 2019, 29: 1900314

23 Li H, Cao J, Zheng W, et al. Controlled synthesis of topological insulator nanoplate arrays on mica. J Am Chem Soc, 2012, 134: 6132-6135

24 Zheng $\mathrm{W}$, Xie $\mathrm{T}$, Zhou $\mathrm{Y}$, et al. Patterning two-dimensional chalcogenide crystals of $\mathrm{Bi}_{2} \mathrm{Se}_{3}$ and $\mathrm{In}_{2} \mathrm{Se}_{3}$ and efficient photodetectors. Nat Commun, 2015, 6: 6972

25 Wang F, Li L, Huang W, et al. Submillimeter $2 \mathrm{D} \mathrm{Bi}_{2} \mathrm{Se}_{3}$ flakes toward high-performance infrared photodetection at optical communication wavelength. Adv Funct Mater, 2018, 28: 1802707

26 Chuang CHM, Brown PR, Bulović V, et al. Improved performance and stability in quantum dot solar cells through band alignment engineering. Nat Mater, 2014, 13: 796-801

27 Wu H, Kang Z, Zhang Z, et al. Interfacial charge behavior modulation in perovskite quantum dot-monolayer $\mathrm{MoS}_{2} 0 \mathrm{D}-2 \mathrm{D}$ mixeddimensional van der Waals heterostructures. Adv Funct Mater, 2018, 28: 1802015

28 Zhang $\mathrm{H}$, Liu CX, Qi XL, et al. Topological insulators in $\mathrm{Bi}_{2} \mathrm{Se}_{3}$, $\mathrm{Bi}_{2} \mathrm{Te}_{3}$ and $\mathrm{Sb}_{2} \mathrm{Te}_{3}$ with a single Dirac cone on the surface. Nat Phys, 2009, 5: 438-442
29 Bianchi M, Guan D, Bao S, et al. Coexistence of the topological state and a two-dimensional electron gas on the surface of $\mathrm{Bi}_{2} \mathrm{Se}_{3}$. Nat Commun, 2010, 1: 128

30 Peng H, Dang W, Cao J, et al. Topological insulator nanostructures for near-infrared transparent flexible electrodes. Nat Chem, 2012, 4: 281-286

31 Furchi MM, Pospischil A, Libisch F, et al. Photovoltaic effect in an electrically tunable van der Waals heterojunction. Nano Lett, 2014, 14: 4785-4791

32 Ji J, Choi JH. Layer-number-dependent electronic and optoelectronic properties of $2 \mathrm{D} \mathrm{WSe} \mathrm{W}_{2}$-organic hybrid heterojunction. Adv Mater Interfaces, 2019, 6: 1900637

33 Doan $\mathrm{MH}$, Jin Y, Adhikari S, et al. Charge Transport in $\mathrm{MoS}_{2}$ / $\mathrm{WSe}_{2}$ van der Waals heterostructure with tunable inversion layer. ACS Nano, 2017, 11: 3832-3840

34 Lee I, Rathi S, Lim D, et al. Gate-tunable hole and electron carrier transport in atomically thin dual-channel $\mathrm{WSe}_{2} / \mathrm{MoS}_{2}$ heterostructure for ambipolar field-effect transistors. Adv Mater, 2016, 28: 9519-9525

35 Cheng R, Li D, Zhou $\mathrm{H}$, et al. Electroluminescence and photocurrent generation from atomically sharp $\mathrm{WSe}_{2} / \mathrm{MoS}_{2}$ heterojunction p-n diodes. Nano Lett, 2014, 14: 5590-5597

36 Yang $\mathrm{T}$, Zheng $\mathrm{B}$, Wang $\mathrm{Z}$, et al. Van der Waals epitaxial growth and optoelectronics of large-scale $\mathrm{WSe}_{2} / \mathrm{SnS}_{2}$ vertical bilayer $\mathrm{p}-\mathrm{n}$ junctions. Nat Commun, 2017, 8: 1906

37 Ramasubramaniam A. Large excitonic effects in monolayers of molybdenum and tungsten dichalcogenides. Phys Rev B, 2012, 86: 115409

$38 \mathrm{Yu} \mathrm{Y,} \mathrm{Hu} \mathrm{S,} \mathrm{Su} \mathrm{L,} \mathrm{et} \mathrm{al.} \mathrm{Equally} \mathrm{efficient} \mathrm{interlayer} \mathrm{exciton} \mathrm{re-}$ laxation and improved absorption in epitaxial and nonepitaxial $\mathrm{MoS}_{2} / \mathrm{WS}_{2}$ heterostructures. Nano Lett, 2015, 15: 486-491

39 Chiu $\mathrm{MH}$, Zhang C, Shiu HW, et al. Determination of band alignment in the single-layer $\mathrm{MoS}_{2} / \mathrm{WSe}_{2}$ heterojunction. Nat Commun, 2015, 6: 7666

$40 \mathrm{Wu} \mathrm{H}, \mathrm{Si} \mathrm{H}$, Zhang Z, et al. All-inorganic perovskite quantum dotmonolayer $\mathrm{MoS}_{2}$ mixed-dimensional van der Waals heterostructure for ultrasensitive photodetector. Adv Sci, 2018, 5: 1801219

41 Huang Y, Zhuge F, Hou J, et al. Van der Waals coupled organic molecules with monolayer $\mathrm{MoS}_{2}$ for fast response photodetectors with gate-tunable responsivity. ACS Nano, 2018, 12: 4062-4073

42 Nourbakhsh A, Zubair A, Dresselhaus MS, et al. Transport properties of a $\mathrm{MoS}_{2} / \mathrm{WSe}_{2}$ heterojunction transistor and its potential for application. Nano Lett, 2016, 16: 1359-1366

43 Srivastava PK, Hassan Y, Gebredingle Y, et al. Multifunctional van der Waals broken-gap heterojunction. Small, 2019, 15: 1804885

44 Das S, Prakash A, Salazar R, et al. Toward low-power electronics: tunneling phenomena in transition metal dichalcogenides. ACS Nano, 2014, 8: 1681-1689

45 Fan S, Vu QA, Lee S, et al. Tunable negative differential resistance in van der Waals heterostructures at room temperature by tailoring the interface. ACS Nano, 2019, 13: 8193-8201

46 Fan S, Yun SJ, Yu WJ, et al. Tailoring quantum tunneling in a vanadium-doped $\mathrm{WSe}_{2} / \mathrm{SnSe}_{2}$ heterostructure. Adv Sci, 2020, 7: 1902751

47 Guo Z, Chen Y, Zhang H, et al. Independent band modulation in $2 \mathrm{D}$ van der Waals heterostructures via a novel device architecture. Adv Sci, 2018, 5: 1800237

48 Wang $\mathrm{X}$, Wang $\mathrm{P}$, Wang J, et al. Ultrasensitive and broadband $\mathrm{MoS}_{2}$ photodetector driven by ferroelectrics. Adv Mater, 2015, 27: 
6575-6581

49 Long M, Gao A, Wang P, et al. Room temperature high-detectivity mid-infrared photodetectors based on black arsenic phosphorus. Sci Adv, 2017, 3: e1700589

50 Liu H, Li D, Ma C, et al. Van der Waals epitaxial growth of vertically stacked $\mathrm{Sb}_{2} \mathrm{Te}_{3} / \mathrm{MoS}_{2} \mathrm{p}$-n heterojunctions for high performance optoelectronics. Nano Energy, 2019, 59: 66-74

51 Yao J, Zheng Z, Yang G. Layered-material $\mathrm{WS}_{2} /$ topological insulator $\mathrm{Bi}_{2} \mathrm{Te}_{3}$ heterostructure photodetector with ultrahigh responsivity in the range from 370 to $1550 \mathrm{~nm}$. J Mater Chem C, 2016, 4: 7831-7840

52 Liu H, Zhu X, Sun X, et al. Self-powered broad-band photodetectors based on vertically stacked $\mathrm{WSe}_{2} / \mathrm{Bi}_{2} \mathrm{Te}_{3} \mathrm{p}-\mathrm{n}$ heterojunctions. ACS Nano, 2019, 13: 13573-13580

Acknowledgements This work was supported by the National Nature Science Foundation of China (21825103 and 51727809), Hubei Provincial Natural Science Foundation of China (2019CFA002) and the Fundamental Research Funds for the Central Universities (2019kfyXMBZ018). The authors thank the Analytical and Testing Centre of Huazhong University of Science and Technology.

Author contributions Wang $\mathrm{F}$ and Huang $\mathrm{Y}$ fabricated the devices. Zhang Y and Zhang Q did the AFM and Raman measurements, respectively. Wang $\mathrm{F}$ performed the characterization and wrote the manuscript. Zhai T supervised the project. Wang F, Luo P, Yuan L and Zhai $\mathrm{T}$ discussed the manuscript and made the revision.

Conflict of interest The authors declare that they have no conflict of interest.

Supplementary information Supporting data are available in the online version of the paper.

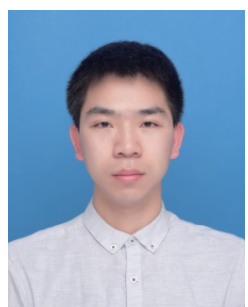

Fakun Wang received his BSc degree in mineral processing engineering from Central South University in 2016. He is studying for his $\mathrm{PhD}$ degree at Huazhong University and Technology under the supervision of professor Tianyou Zhai. His work focuses on the controllable synthesis of low-dimensional inorganic materials, and their promising applications in optoelectronics.

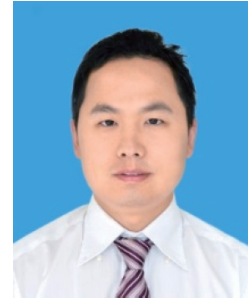

Tianyou Zhai received his BSc degree in chemistry from Zhengzhou University in 2003, and $\mathrm{PhD}$ degree in physical chemistry from the Institute of Chemistry, Chinese Academy of Sciences (ICCAS) under the supervision of Prof. Jiannian Yao in 2008. Afterwards he joined the National Institute for Materials Science (NIMS, Japan) as a postdoctoral fellow of Japan Society for the Promotion of Science (JSPS) in Prof. Yoshio Bando's group and then as a researcher of the International Center for Young Scientists (ICYS) within NIMS. Currently, he is a chief professor of the School of Materials Science and Engineering, Huazhong University of Science and Technology. His research interests include the controlled synthesis and exploration of fundamental physical properties of inorganic functional nanomaterials, as well as their promising applications in energy science, electronics and optoelectronics.

\section{带结构工程隧穿异质结用于高性能可见和近红外 光探测}

王发坤, 罗鹏, 张悦, 黄玉, 张庆福, 李渊, 翟天佑 ${ }^{*}$

摘要 隧穿异质结因其先进的光学灵敏度、可定制的探测范围以 及均衡的光电性能而正逐渐成为一种光电探测的通用体系结构. 但是, 现有的隧穿异质结主要在可见光波段工作, 很少能实现近红 外光探测. 本文利用具有互补带隙的 $\mathrm{WSe}_{2}$ 和 $\mathrm{Bi}_{2} \mathrm{Se}_{3}(1.46$ 和 $0.3 \mathrm{eV})$ 设 计了一种能同时实现高性能可见和近红外光探测的新型裂隙隧穿 异质结. 由于能带结构的重新排列, $\mathrm{WSe}_{2} / \mathrm{Bi}_{2} \mathrm{Se}_{3}$ 异质结构展现出了 低于 $\mathrm{pA}$ 量级的暗电流和以隧穿为主的光电流. 我们设计的隧穿异 质结对 $532 \mathrm{~nm}$ 可见光和 $1456 \mathrm{~nm}$ 近红外光的比探测度高达 $7.9 \times 10^{12}$ 和 $2.2 \times 10^{10}$ Jones. 本研究为构建用于高性能宽带光探测的范德瓦尔 斯隧穿异质结构提供了一种新的带结构工程途径. 